\title{
Study on the Infiltration of Multimedia and Internet Technology in Piano Playing \\ Yidong Wu
}

Shandong University Of Arts (China Shandong 250300)

Keywords: Multimedia; Internet technology; Piano playing

\begin{abstract}
With the continuous improvement of the level of modernization in our country, the current multimedia technology and network technology are also becoming mature day by day whose application in piano performance activities has become more and more frequent. Based on the current situation of piano teaching and performance, the paper analyzes the existing problems in the traditional piano teaching mode, then introduces the advantages of using multimedia technology and network technology in piano teaching, and finally with the above content for multimedia technology and network technology, this paper judges the current situation of infiltration of multimedia and Internet technology in Piano Playing, and it also hopes to create the conditions for the overall improvement of piano playing.

With the popularization of multimedia technology and network technology in our country, it has brought tremendous influence and change to the traditional piano teaching activities at present. Whether it is from the teaching mode or from the teaching content, multimedia technology and network technology have brought fresh blood, but there are some new problems in the application process of multimedia technology and network technology. In order to further analyze the value of multimedia technology and network technology in piano teaching, this paper introduces the existing problems in the traditional piano teaching mode.
\end{abstract}

\section{Part One Problems in Traditional Piano Teaching Mode}

\section{It is Difficult to Mobilize Students' Subjective Initiative}

Among the traditional piano teaching modes, teachers tend to pay more attention to the mastery of students' basic knowledge and the effect of their skills, but pay less attention to their interests and positions in learning. This often leads to the students' understanding of piano works is too superficial, or the understanding has more obvious utilitarian. In the process of piano playing, if the performer can not understand the connotation and background of the work in depth, while only perform the complicated performance merely for the sake of "dazzle skills", it will not only fail to achieve good performances, but may even cause students to fall into erroneous playing areas, and it can not play their own strength and advantages.

\section{Students are not Enthusiastic on the Piano Practice}

Piano practice is an important part of teaching, which means teacher should leave time to students, and students will get all the learned knowledge that can become the key link of their ability. However, in view of the actual teaching situation, most students often have insufficient goals in free practice. Some students are not very interested in the piano lessons selected by the teacher, but because they are forced to practice so they can only do the task after completing the basic standards of practice, and there is no interest and enthusiasm at all. In addition, in the process of playing to enhance the effectiveness of the practice, some teachers may require students to conduct a unified large-scale exercises, so that neither highlight the students' subjectivity, but also neglect the personality of students that will result in students being nurtured in a model that affects the development of individual awareness of students, and it is not conducive to the overall level of personal piano performance in the future.

\section{The Professional Quality of Teachers has a Greater Impact}

In traditional piano education mode, teachers are the main body of teaching who assumes almost all of the teaching tasks. From the imparting of knowledge, skill learning and personal training track selection and other aspects, all are controlled by teachers. The result must be that a teacher's 
professional qualities directly determines the level of student learning. With the advent of the Internet age, the problems existing in these traditional teaching modes are gradually exposed, and searching for new changes has become an urgent task in teaching.

\section{Part Two Application Advantages of Multimedia Technology and Internet Technology in Piano Teaching}

\section{The Role in Music Appreciation}

The development of multimedia technology and Internet technology has ended the teaching of the day when a recording machine or a piano can complete all of the work, and it realizes the real change in the classroom teaching mode. In some teaching activities, students are always eager to see the high-quality piano often to see their idol master. However, in most of the actual teaching situations, universities do not have this condition, so they can only perform works through multimedia. Through multimedia technology, they can also be restored to a certain extent, which can also stimulate students' enthusiasm for learning and learn the attractiveness and charm of piano works.

\section{Application in Digital Piano Collective Teaching}

Digital piano collective learning is the main trend of integration of multimedia technology and Internet technology. In some college teaching, limited to the financial pressure and equipment procurement difficulty and other aspects of the problem, not every student can have a piano of his own, then teachers must create conditions through technical simulation to ensure that each student can get the corresponding practice, and then the digital piano comes into being. Digital piano software simulation can solve the problem of inadequate equipment, and there can also be a variety of adjustments in order to adapt to different playing styles and needs.

\section{Multimedia Piano Composition System}

The multimedia piano composition system is composed by software simulation, which is not only convenient and quick but also has good plasticity, and it can be deleted at any time, and even can be performed after the completion of its own, and it has also been widely recognized by students.

\section{Part Three The Infiltration of Multimedia and Internet Technology in Piano Playing}

\section{The Application of Multimedia Technology in Piano Playing}

\section{Alternating Symphony Orchestra, Saving Cost}

Traditional piano concerts must be accompanied by high-quality orchestral symphony in order to achieve a good performance. However, in the actual performance process, due to the large number of symphony orchestra performances and high cost, the stage is more difficult to apply. Through the processing of multimedia technology, the symphony sound can be directly played out by using the sound system. This not only greatly enhances the effect of the performance, but also effectively saves the cost and accomplishes the task of completing the performance within a certain cost and lays the foundation for promoting the piano performance basis.

\section{Achieving Platform Concert}

Achieving platform concerto also plays a role in the penetration of multimedia technology in the piano. Due to the limitation of cost and venue, the traditional performance mode often can only achieve the performance of a single platform. The organic integration of venue and lighting effects through multimedia not only realizes the merging of multiple platforms, but also adjusts it to the best performance patterns, and thus reflects the application of science and technology value and achieves good performance results.

\section{Creating a More Subtle Performance}

Exquisite performance is the lifelong pursuit of every pianist. Multimedia applied to the piano performance can further enhance the performance of the playing through the lighting, projection equipment and rhythm changes, and it not only allows the audience to experience more under the influence of a variety of senses, but also for the performance level of the player to enhance the 
performance of the piano that also has a certain role in promoting. This shows that multimedia technology in the creation of subtle performance is also of great value.

\section{The Application of Internet Technology in Piano Playing}

Internet technology refers to the integration of computer technology and network information technology, which is widely used in piano performance and teaching. It can be divided into the following aspects.

\section{Carrying out Teaching Work by Using Online Resources}

The advantages of using online resources to carry out teaching work include three aspects. Firstly, the network resources have the characteristics of continuous updating, and the teaching process will not appear the problems, such as too little information and the old case, which is an objective solution to the problems of the traditional teaching activities and practices out of touch. Secondly, network resources have characteristics of certain teaching convenience and rich channels. By using television broadcasting, Internet platform and other kinds of mobile platforms, the rich angles and non-dead-end education can be realized. This can improve the comprehensive utilization efficiency of students' time, and can improve the training effect. Finally, the network resources have the characteristics of disregarding time and space in teaching, and it can reduce the cost of students' study and reduce the burden on families, which also plays a certain role in the promotion of education.

\section{Collecting a Variety of Piano Information by Using the Internet}

Collecting a variety of piano information in Internet is often used to study piano learning methods. Compared with the traditional learning mode, the collection of piano data through the Internet can help learners recognize different cultural differences and geographical differences in the teaching resource base, and at the same time, students can widely learn different piano knowledge and theories to form their own playing style. In addition, for beginners, different piano information can stimulate their enthusiasm for learning and improve their learning initiative. This not only can solve the traditional teaching mode in which the style of the teacher is the embarrassment of the student's style, but also conducive to the specialization, targeting and differentiation of the piano teaching, which is important for promoting the overall healthy development of the piano playing industry in our country.

\section{Promoting Piano Learning and Communication by Using the Internet}

The Internet has two levels of significance in promoting piano learning and communication. On the one hand, students will inevitably encounter various problems in their self-study. If they are not digested promptly, they will accumulate more and more, which leads to no improvement in students' playing skills. Through the Internet platform, problems can be promptly resolved through communication and disguise, and it can reduce the difficulty of learning in disguise. On the other hand, in the process of communication, learners can spontaneously form groups and find emotional sustenance and co-advancing partners in boring study and practice, which is also helpful for the eventual improvement of performance and skills.

In summary, the application of Internet technology in piano performance not only makes the searching of information resources more convenient, but also uses the Internet channel to achieve piano communication and promotes platform learning. This can stimulate students' enthusiasm for learning and enhance performance. Based on the current situation of infiltration of multimedia technology and Internet technology in piano playing, this paper also mainly studies its role in replacing symphony orchestra, accomplishing platform concerto, creating exquisite stage effect and promoting exchange learning, and also hopes to create conditions for carrying out smoothly piano playing and teaching activities by providing new ideas for the industry to achieve full and rapid and sustainable development.

\section{References}

[1] Ying Xiang. The introduction of multimedia and Internet technology to the penetration of piano teaching and playing[J].Good Parents, 2017(66):233.

[2] Songye Cheng. The introduction of multimedia and Internet technology to the penetration of 
piano teaching and playing[J].Art and Technology,2017,30(08):391.

[3] Qinglan Du. The introduction of multimedia and network technology to the penetration of piano teaching and playing[J].Journal of Changchun Normal University,2017,36(10):158-159.

[4] Wei Li, Yuanyuan Su. The penetration of multimedia and network technology to the teaching and playing of the secondary vocational piano[J].Information Technology Education in China,2014(12):28+30.

[5] Wei Li, Xia Dan. The introduction of multimedia and network technology to the penetration of piano teaching and playing[J].Scientific and Technological Information (Science and Research),2008(05):38+100. 